P. GRADY MOREIN, JOSEPH F. BOYKIN, JR., H. LEA WELLS, and JOHNNIE E. GIVENS

\title{
The Academic Library Development Program
}

\begin{abstract}
The Academic Library Development Program is a planned effort to design and pilot test a program which small and medium-size academic libraries may use in evaluating and developing themselves. The project is funded by the Council on Library Resources and receives assistance from the Association of Research Libraries' Office of University Library Management Studies (OMS). It is being conducted by the University of North Carolina at Charlotte (UNCC). This article is derived from a panel discussion entitled "Self-Directed Change in Small and Medium-Size Academic Libraries: A Presentation on the Academic Library Development Program," presented at the ACRL College Libraries Section meeting on July 20, 1976, in Chicago during the ALA annual conference.
\end{abstract}

\section{$\mathbf{T}$}

HE PURPOSE OF THIS ARTICLE is to describe the Academic Library Development Program and to report on the progress of the project. As a first step, it is perhaps useful to distinguish between the term "project," which we define as the efforts devoted to designing and testing, and "program," which is the product intended to result from those efforts. In describing our experience, therefore, we shall discuss, first, the

P. Grady Morein, project coordinator, is associate professor of library science, North Carolina Central University, Durham. Joseph H. Boykin, Jr., principal investigator, is director of the library, University of North Carolina at Charlotte. H. Lea Wells, study team chairperson, was library circulation coordinator, UNCC, when the report was presented and is presently a student in the School of Library Science, University of North Carolina at Chapel Hill. Johnnie E. Givens, advisory committee member, was librarian, Austin Peay State University, Clarksville, Tennessee, and is presently executive director, Southeastern Library Association. project: how it originated, why it was created, how it was conducted, and what is expected of it. Following it, we shall describe the program that has been developed. We shall conclude with a review of what the project and the program might mean to academic librarianship.

\section{The Project}

The Academic Library Development Program originated in response to a perceived need. In recent years academic librarians have become increasingly aware of the need to develop more effective means of dealing with the rapid and hectic changes which are besetting not only librarianship, but every type of organization and institution. In 1972 Robert Haro pointed to the lack of adequately defined methods for coping with change within academic librarianship. ${ }^{1}$ A year later Arthur M. McAnally and Robert B. Downs created a considerable stir within the profession by demonstrating a number of changes which were having a significant impact 


\section{8 / College d Research Libraries • January 1977}

upon the role of university library directors. ${ }^{2}$ The authors described numerous changes occurring in the following categories: growth in enrollment, changes in the presidency, proliferation in university management, changes in the world of learning and research, the information explosion, hard times and inflation, planning and budgeting, technology, changing theories of management, unionization, increasing control by state boards, and no national system for information. Similar conditions were reported by Booz, Allen and Hamilton in their study of the Columbia University Libraries. ${ }^{3}$

While each of these studies focused on larger university libraries and while some of the conditions have already taken a different turn, most of the factors identified are also affecting the small and medium-size academic libraries. These smaller institutions are facing internal and external changes of similar content and equal magnitude. Changes in enrollment patterns, inflation, reduced budgets, changing theories of management, the information explosion, and new technology are all having an impact upon academic libraries of every size.

It isn't only librarianship, however, which is experiencing rapid and hectic change. The increasing size, complexity, and interdependency of society and the ecosystem is affecting every sector of our society. Government, business, medicine, religion, and education, for example, are all experiencing what Peter Drucker has called the "end of continuity" and face a new "age of discontinuity." There is no question that severe, unprecedented change is becoming more widespread. The question which needs to be addressed is: What can be done to guide and shape change in ways which will be of greatest benefit? Until recently, the tools, the knowledge, skills, or proper attitude for dealing with change and discontinuity have not been available. This problem is being resolved, however.

Methods for coping with change are being developed; methods which focus on providing the things we lack mostknowledge, skills, attitudes. The techniques are known by several names. Planned Change, Action Research, and Organization Development are the terms used most often to designate the programs developed in recent years to assist groups and organizations to direct change more effectively. These programs originated primarily in business organizations. One of the best known and most widely used organization development programs is the Managerial Grid. ${ }^{5}$ Programs have also been developed and applied within the public sector, ${ }^{6}$ in secondary schools, ${ }^{7}$ in higher education, ${ }^{8}$ and in university and research libraries. ${ }^{9}$

The program for libraries is entitled the Management Review and Analysis Program (MRAP). It was developed by the Association of Research Libraries' Office of University Library Management Studies (OMS) as an assisted selfstudy approach to improving the management of large university and research libraries. Twenty-two libraries have applied MRAP thus far. Participants report that application of the Program results in improved management practices and staff capabilities. These, in turn, lead to better operations and services. ${ }^{10}$

These were the developments which motivated the Council on Library Resources to support the Academic Library Development Program. The need for tools and methods, coupled with the success of organization development programs, especially the Management Review and Analysis Program, prompted the Council to fund a project aimed at developing a program for smaller academic libraries. Various professional associations, including the Association of College and Research Libraries, had expressed to Council an interest in de- 
veloping, cooperatively, a program to meet the distinctive needs of the smaller academic library. Numerous college libraries had asked OMS if it were possible to modify the MRAP processes and to make it available for their use. In response to this interest, the Council funded a project at the University of North Carolina at Charlotte with the stipulation that a process be designed that capitalizes upon the MRAP experience and draws upon other relevant development programs within and outside librarianship.

\section{Methodology}

The project consists of two elements, a design and a test of a program. It was decided that the best results could be achieved by conducting these two tasks concurrently using an action research approach. Action research is essentially a systematic fact-finding and experimentation process which utilizes both experts and practitioners. Consequently, the project was conducted on-site within a medium-size academic library. The library staff furnished practitioner input while expert contribution was obtained from several sources. A coordinator with a background in management and librarianship was engaged to direct the project. The coordinator received assistance from the director of the Office of University Library Management Studies and consulted with librarians who had experience with MRAP and other development programs. In addition, an advisory committee was created to provide guidance. The committee is made up of librarians, library educators, college presidents, and representatives of professional associations.

A key consideration in initiating the program was the selection of the host library. Because of the role which the library was to play in designing as well as testing the program, it was essential that the library possess adequate resources and talent. Equally important was the need for a strong commitment on the part of the library staff, the library administration, and university officials. Other criteria include appropriate size, relatively stable operating conditions, and able management. (The program is intended to "develop" libraries, not rescue them from collapse.)

The University of North Carolina at Charlotte (UNCC) amply meets these criteria. The university is one of the sixteen institutions comprising the University of North Carolina System. It has an FTE enrollment of approximately 6,200 with a faculty of about 410 . While enrollment continues to rise, the rate of growth has declined in the last few years. The institution is relatively new, having begun in 1946. It is, however, approaching maturity. In addition to a full undergraduate curriculum, master's degrees are offered in eight areas. The university administration is considered progressive and actively supports the library.

Like the institution it serves, the library has expanded rapidly, especially during the 1960s. It presently contains 225,000 monographs, more than 60,000 government documents, 300,000 pieces of microforms, and 5,000 pieces of audio-visual material. Its serial subscriptions number 4,500 . The budget exceeds $\$ 1,000,000$ with more than $\$ 500,000$ being expended for material. There are sixteen library faculty positions and forty support positions on the staff.

Both university officials and library staff view the project as an excellent opportunity for the library to assess and improve its performance, while making a contribution to the profession. They recognize that the university and the library are entering a new stage of development characterized by shifting emphasis and a higher degree of uncertainty. They would like to prepare themselves to meet these changes directly and positively.

The library staff acknowledges that 
many of its processes and practices evolved with only limited planning and may now be outmoded or less effective. In addition, they believe that efforts should be made to acquire the new knowledge and skills needed to meet the challenges now occurring within the university and the library.

\section{Design of the Program}

With these considerations before it, the Council on Library Resources approved UNCC's request to host the project, and specified that the library director would serve as principal investigator. A project coordinator was recruited, and the design began. The first step in the design was a planning session involving the principal investigator, the project coordinator, the assistant director of the library, and the OMS director, serving as consultant. These individuals established goals, determined general strategy for achieving those goals, and constructed a schedule of events.

The project coordinator then spent several weeks studying the literature, reviewing various programs which might relate to this program, and discussing the Management Review and Analysis Program with individuals who had participated in the MRAP. With this information as a foundation the coordinator constructed a general framework for the program. At this point, a meeting of the advisory committee was called. The general outline of the program was presented to the committee and thoroughly discussed. With the approval of the committee the coordinator then began detail design efforts.

The procedure followed at this stage was for the coordinator to continue surveying the literature and talking with colleagues and library staff until he had a good idea of what processes, procedures, techniques, and aids were feasible. He would then discuss various alternatives with the OMS director until agreement on a specific approach was achieved. Following this the coordinator would write a description of the processes, procedures, and directions. These would then be circulated to the principal investigator, the OMS director, the assistant director of the library, and, perhaps, different members of the UNCC library staff. These individuals would analyze the description to determine if any modification or clarification was necessary. The directions were then sent to the study groups for their review. They would be examined for understandability and workability. When the study groups were satisfied that the process was workable, they began their analysis and testing.

\section{Test of the Program}

The program was tested for workability and for results. In applying the program, the study groups verified the feasibility of the processes, procedures, and worksheets. The program was also checked for its capacity to produce results. This was achieved by reviewing the output of each analysis to determine if the program furnished adequate direction and guidance.

Both of these tests produced a number of constructive modifications in the program. In some instances a procedure may have been too restrictive; in others it was too broad. There were occasions when directions or worksheets were unclear. From time to time it was necessary to furnish more background information on a process or recommend additional reading material. These and other adjustments are being made in the program. It is anticipated that further refinements will have to be incorporated when the project is completed. Plans are being made to have the study groups and members of the library staff critique the program at some later date when they have had an opportunity to remove themselves from the pressures of immediate tasks. 


\section{Summary of the Project}

While the project is not yet complete, two results have begun to emerge. First, there are definite indications that the UNCC Library is improving its performance in a number of ways related to the program. The staff has already begun to adopt some of the techniques employed by the study groups. One of the units, for example, is using brainstorming as a means of assessing its particular needs. Another sign of the impact of the program is an increase in the amount and quality of communication within the library. Staff members are discussing problems more openly and more constructively. They are more inclined to look for solutions, rather than to place blame. Other changes are occurring as the program progresses, and there is considerable anticipation on the part of the staff that the final recommendations will lead to even more significant improvements.

The second outcome of the project is the program itself. The primary intent of the project was to design and test a program which small and medium-size academic libraries could use in improving their performance. A basic program has been designed and is currently undergoing testing. Preliminary tests indicate the program is feasible for use by a medium-size library. In the remainder of this article the general features of the program which were applied at the University of North Carolina at Charlotte will be described. Some conclusions which may be drawn as a result of the UNCC experience with the program will then be suggested.

\section{The Program}

Perhaps the best way to begin describing the program is to state the goals in designing an Academic Library Development Program (ALDP). The principal objective in formulating the processes, procedures, and worksheets was to create a program which would:
1. Provide a means for libraries to improve their performance through more effective use of their human and material resources.

2. Furnish processes, procedures, worksheets, and guidelines which a library can follow in evaluating its services, operations, and management practices.

3. Create within the library a more positive, "proactive" attitude toward change.

4. Increase the library's problem-solving capabilities.

5. Expand the staff's knowledge, skills, and abilities through an experiential "learning-by-doing" approach.

6. Furnish a model process which will enable academic libraries to develop more systematic, analytic work methods.

7. Develop the interpersonal skills of the staff so that individuals can work more effectively in group situations.

The rationale behind the program, as stated earlier, is that increasing complexity and interdependence among the numerous segments of society and the ecosystem are placing greater and greater pressure upon all organizations to develop more systematic, collaborative approaches for dealing with change. The program, therefore, furnishes a means of developing the requisite knowledge and skill for coping with change and developing more effective working and operating practices.

\section{Approach}

The approach employed by the program is a self-study process involving the entire library staff in various ways. There are several reasons for choosing this method. In the first place, the program is intended to develop the entire staff. The more the staff participates in the study, the more they will profit from the experience. Another reason for 
having the staff conduct the analysis is that such a procedure makes it possible to use the most competent members in the most effective way, regardless of position or status. A third reason for making wide use of the staff is that different members can provide diverse perspective on issues. Another advantage of the self-study approach is that when staff members are involved in identifying problems and developing solutions they are more likely to accept and support those solutions.

The principal means of involving the staff in the analysis is through study groups. Two types of groups are utilized. One is called a study team. This group holds ultimate responsibility for the conduct of the study. In addition to performing various analyses, the study team directs other efforts related to the study. The second type of study group is called a task force. Its role is to conduct specific analyses, whereas the study team engages in more general assessments and coordinates the work of the four task forces used in the study. The size of the study groups may vary somewhat, but should include at least four members. UNCC began with a fiveperson study team, but enlarged it to seven. The task forces consisted of six members including a member of the study team who served as chairperson. Both professional and support staff served on study groups. The chairperson of the study team was a nonlibrarian in a support staff position.

\section{The Study Modules}

For purposes of analysis, the study is divided into eight modules. Four of the modules focus on general issues and provide a foundation for the remaining specific analyses. The general analyses are conducted by the study team, while the specific analyses are performed by task forces. Included in the general modules are: an historical review, an environmental analysis, a needs assessment, and an analysis of library goals and objectives. These four reviews are begun in sequence; however, it isn't necessary to complete one before starting another. UNCC spent approximately four months on this phase of the self-study.

The four specific modules are: (1) Management Structure and Processes; (2) Human Resource Development and Use; (3) Library Resources and Services; and (4) Future Demands for Technology and Facilities. The titles of the third and fourth modules are descriptive of the content of these analyses. However, the titles of the first and second may not reflect the scope of these two modules. Management Structure and Processes, for example, includes reviews of planning, budgeting, and policy-making practices, as well as an assessment of the organizational structure of the library. The Human Resource Development and Use consists of an examination of personnel and staff development practices, supervision, and leadership. As with the general modules, these analyses are conducted in an overlapping sequence. Each specific analysis is performed by a single task force. In the Charlotte study each task force was allotted six weeks to complete its study.

\section{The Process of Analysis}

An analytical process is specified by the program. Each study group follows the same basic pattern which includes the following steps:

1. Plan.

2. Organize.

3. Collect data.

4. Evaluate the situation.

5. Develop methods for improving the situation.

6. Construct a report.

7. Review the analysis and repeat the process if necessary.

8. Revise the report, then circulate to the entire staff for review.

9. Consider staff response, revise and 
polish report, then issue it.

The first six steps constitute the core of the analytical process. Every analysis begins with a period of planning. Each study group must establish goals and determine means of achieving those goals. Once the means have been established, it is necessary to organize-to divide the work into tasks and to select assignments. Generally, a group will divide into pairs or triads for data collection and preliminary evaluation. Data collection is the next step. This may involve locating documents, conducting surveys, or interviewing library staff, university officials, faculty, or students. Following the collection of data is an evaluation of the situation. The program specifies that the evaluation should identify strengths as well as weaknesses. If problems are discovered, the group must search for methods of resolving them. The next step is to construct a report which describes the situation, identifies strengths and weaknesses, and recommends changes which would improve performance.

Once these core steps are completed, it is necessary to review all efforts to assure that adequate data were gathered, that the evaluation was thorough, and that the recommendations are realistic and feasible. The entire study group is responsible for the quality of the analysis. The complete group, therefore, always reviews the efforts of sub-groups as well as re-examining its own work. Sometimes, the review indicates a need to repeat the entire analytical process beginning with a reconsideration of goals and strategy. The UNCC experience suggests that original goals will sometimes be ill-defined or misdirected. There were, for example, occasions in which a preliminary report was completed only to find that a major area of importance had been overlooked. In such cases, it was necessary to reorganize the work, collect additional data, reevaluate, and rewrite the report.
Even when the entire process does not have to be repeated, a certain amount of rework and revision is generally required of each analysis. At some point, however, the study group completes its analysis. The program recommends that at this stage the report should be circulated to library staff members for their review. In the UNCC study, most circulated reports were found to be satisfactory to the staff. In a few instances, however, staff members were able to supply additional information or clarify certain points in a way that improved the analysis. The last step in the process, therefore, is to consider staff response, revise and polish the report, then issue it.

\section{Summary of the Program}

This, then, is the program which has been developed to assist small to medium-size academic libraries in evaluating themselves and in improving their performance and their abilities to cope with change. The program employs a self-study approach emphasizing considerable staff involvement as a means of achieving effective evaluation and as a method of developing more systematic and collaborative work practices within the library. Essentially, the program consists of detailed processes, procedures, guidelines, evaluation criteria, worksheets, schedules, and recommended readings for the library to follow in analyzing and developing itself.

\section{Conclusions}

Academic librarians have for some time realized the need to improve their effectiveness and their ability to cope with changing conditions. Pressures for improvement are appearing from all directions. The information explosion, declining resources, continued inflation, rapid technological development, and changing demands within higher education are but a few of the forces which are making it increasingly urgent 
that academic libraries improve their services, operations, and management practices.

Librarians within higher education not only recognize the need, they are willing and anxious to cope with the forces of change. In the past decade or so academic libraries have taken a number of steps aimed at increasing their effectiveness. They have introduced new technology, especially in the areas of computerized processing and circulation. They have engaged in internal reorganization. They have introduced new management techniques such as Planning Program Budgeting (PPB) and operations research. They have established cooperative networks for sharing resources and reducing duplication of efforts. And they have initiated numerous management and staff development programs.

All of these efforts have contributed toward improving some aspects of library performance. Each of them, however, focuses on limited issues as the principal means of resolving very complex problems. The difficulties created by novel, rapid change call for broad improvement strategies. Academic libraries have entered a new era which requires a greater appreciation of the milieu in which a library operates. Single issue or limited issue approaches are not enough. In order to deal with the complex problems facing librarianship, all members of these organizations will have to develop a broader perspectivea systems viewpoint regarding the role and function of these institutions. In addition, most members will have to develop new knowledge and new skills if the libraries expect to cope effectively with the new forces of change.

It is these issues which the Academic Library Development Program addresses. It focuses on the entire organization: on services, operations, goals and objectives, planning, budgeting, tech- nology, facilities, staff development, leadership, and interpersonal relationship. It emphasizes evaluation and development of the whole organization. And it provides a means for expanding the knowledge and skills of the staff.

While the UNCC project is not yet complete, it is obvious that the program is achieving benefits for the University of North Carolina at Charlotte library. It also appears from the UNCC experience that the program could be useful to other academic libraries. We believe that, given a manual, other libraries could apply the program. The processes, procedures, and guidelines have been designed for application in small to medium-size academic libraries. The UNCC staff has been able to conduct the program with a certain amount of assistance. Through their efforts and contributions the processes have been modified and clarified to improve their feasibility. We are convinced that many other libraries can profit from the program as it now stands. Still, the program could be improved further through additional application within different situations.

A number of academic libraries are experiencing severe discontinuities in the form of "steady-state" or declining conditions. Testing the program in that type of situation would be useful. There is also a need to determine the feasibility of the program for very small libraries. Other unanticipated factors might affect the usefulness of the processes or procedures. Further testing would make it possible to build greater flexibility into the program so that alternative procedures and techniques could be included. This would expand its usefulness. In closing, therefore, we feel that the program has been very beneficial to the University of North Carolina at Charlotte and we suggest that it be developed further and made available to the profession. 


\section{References}

1. Robert P. Haro, "Change in Academic Libraries," College \& Research Libraries 33: 97-103 (March 1972).

2. Arthur M. McAnally and Robert B. Downs, "The Changing Role of Directors of University Libraries," College \& Research $\mathrm{Li}$ braries 34:103-25 (March 1973).

3. Booz, Allen \& Hamilton, Inc., Organization and Staffing of the Libraries of Columbia University (Westport, Conn.: Redgrave Information Resources Corp., 1973).

4. Peter F. Drucker, The Age of Discontinuity, Guidelines to Our Changing Society (New York: Harper \& Row, 1969).

5. Robert R. Blake and Jane S. Mouton, The Managerial Grid (Houston: Gulf Publishing Co., 1964); Building a Dynamic Corporation Through Grid Development (Menlo Park, Calif.: Addison-Wesley, 1969).

6. Larry Kirkharl and Neely Gardner, eds. "Organization Development: A Symposium," Public Administration Review 34:97140 (March/April 1974); Robert A. Zawack and D. D. Warrick, Organization Development: Managing Change in the Public Sector (Chicago: International Personnel Management Association, 1976).

7. R. A. Schmuck, P. J. Runkel, S. L. Saturen, R. Martell, and C. B. Den, Handbook of Organization Development in Schools
(Palo Alto, Calif.: National Press Books, 1972).

8. Ronald K. Boyer and Crockett Campbell, eds., "Organizational Development in Higher Education," Journal of Higher Education 44:339-425 (May 1973).

9. Duane E. Webster, "The Management Review and Analysis Program: An Assisted Self-Study to Secure Constructive Change in the Management of Research Libraries," College of Research Libraries 35:114-25 (March 1974); "Coping with Change: The Challenge for Research Libraries," Minutes of the Eighty-Second Meeting of the Association of Research Libraries, May 11-12, 1973, New Orleans, Louisiana (Washington, D.C.: Association of Research Libraries, 1973), p.41-80.

10. "MRAP: The University of Tennessee, Knoxville, Experience," The Southeastern Librarian 24:22-40 (Fall 1974); Duane E. Webster and Jeffrey Gardner, "Strategies for Improving the Performance of Academic Libraries," Journal of Academic Librarianship 1:13-18 (May 1975); Norman D. Stevens, "The Management Review and Analysis Program at the University of Connecticut," Journal of Academic Librarianship 1:4-10 (July 1975); Michael K. Buckland, ed., "The Management Review and Analysis Program: A Symposium," Journal of Academic Librarianship 1:4-14 (Jan. 1976). 